\title{
Use of fatty amide and anionic surfactant as corrosion inhibitors for carbon steel in different atmospheres
}

\author{
E. Vázquez-Vélez, ${ }^{1}$ J.G. Gonzalez-Rodriguez, ${ }^{2 *}$ M.E. Escalante-Pérez, ${ }^{2}$ \\ J.M. Mendoza ${ }^{2}$ and L. Martínez-Gómez ${ }^{1}$ \\ ${ }^{1}$ Instituto de Ciencias Físicas de la UNAM, Av. Universidad s/n, Chamilpa, 62210 \\ Cuernavaca, Morelos, México \\ ${ }^{2}$ Universidad Autónoma del Estado de Morelos, CIICAP, Av. Universidad 1001, 62209, \\ Cuernavaca, Morelos, México \\ *E-mail:ggonzalez@uaem.mx
}

\begin{abstract}
Sulfonated corrosion inhibitors have been used to protect materials in in-door or out-door storage temporarily. However, the use of environmentally friendly inhibitors becomes a necessity to reduce the environmental impact. In this work, fatty amides and anionic fatty surfactants were synthesized from inedible coconut and palm oil. These active compounds were formulated in natural wax and synthetic oil as vehicles of the anticorrosive formulation. The fatty amides were characterized by FTIR and NMR Spectroscopies. The corrosion behavior of carbon steel covered with these inhibitors was compared with the action of two marked products sulfonate base. Quantification of accelerated corrosion testing of preventive inhibitor coated evaluation was made by weight loss measurements after exposure in a fog chamber, simulating four types of atmospheres, namely marine, industrial-marine, rural and rural polluted. It was found fatty amide inhibitor from palm oil reduces corrosion rate efficiently for carbon steel protecting in rural environment $336 \mathrm{~h}$ with a $98.4 \%$ of efficiency and for a polluted rural environment $168 \mathrm{~h}(98.8 \%)$ in fog chamber. For Prohesion cyclic conditions, the temporary protective layer regularly used to protect until 244 h with $99.8 \%$ of efficiency. XRD patterns of rust samples revealed the presence of $\mathrm{Fe}_{3} \mathrm{O}_{4}$ as the main phase in the film. The SEM micrographs showed that the fatty amide base coating presented an excellent efficiency in the four proposed atmospheres. Finally, this work is the first evaluation study of fatty amides in conditions of accelerated corrosion in the fog chamber.
\end{abstract}

Keywords: atmospheric corrosion, fatty amide inhibitor, fog chamber.

Received: August 2, 2018. Published: February 19, 2019

doi: $\underline{10.17675 / 2305-6894-2019-8-1-11}$ 


\section{Introduction}

Conventional weathering steels have been a material of choice for many types of machinery for almost half a century. The main advantage of their use is that under normal conditions they may be left unpainted, leading to reduced maintenance and environmental costs [1]. Nevertheless, materials degradation due to atmospheric corrosion demands the most attention because there are much metallic equipment exposed to aggressive atmospheres particularly the agricultural machinery [2,3]. Carbon steel is prone to corrosion in rural environments both humid as polluted, and an excessive corrosion in the coastal environments has been observed also. There are a few studies about atmospheric corrosion of carbon steel materials using accelerated corrosion tests in salt spray chamber $[4,5]$. Additionally, accelerated corrosion testing has also evolved since providing information to help determine durability of products, and their quality assurance during manufacturing, to use in product research and development [6].

Oil-based formulations have been used as corrosion inhibitors in order to reduce the atmospheric corrosion damage of metallic surface by decreasing the corrosion rate of metallic materials in order to conserve agricultural machinery and equipment in stock [79]. Ghanbarzadeh [10] reported a mineral oil sulfonation process to obtain calcium sulfonate as temporary coating. Panels were coated and examined for corrosion resistance efficiency in $100 \%$ relative humidity cabinet via ASTM D1784. In the market, there are products based on calcium sulfonate, which are limited by its toxic nature. On the other hand, treatment with vapor phase inhibitors or VCIs (Volatile corrosion inhibitors) offers the advantage of preserving the objects independent of their form and their surface state. Organic substance used as contact inhibitors are compounds such as: Aliphatic, cycloaliphatic, aromatic and heterocyclic amines; amine salts with carbonic, acetic, benzoic, nitrous and chromic salts; organic esters, nitro derives and acetylenic alcohols [11-13].

Nowadays, attention has been focused on the need to design and develop "green corrosion inhibitors" in order to remove the toxic compounds for a sustainable development $[14,15]$. Nitrogen-based organic surfactants such as imidazolines, amides, amido-amines, and amines derived from vegetable oils have been used successfully as inhibitors in oil field applications [16,17]. However, there are no reports on these molecules formulated for atmospheric corrosion. In this work, a "green organic inhibitor" based on a fatty amide and anionic surfactant from coconut and palm oils were formulated at different concentrations with natural wax and mineral oil to be applied as a protective film against atmospheric corrosion of the carbon steel. Then, studies of accelerated corrosion in a fog chamber were performed simulating different atmospheres. 


\section{Experimental Procedure}

\subsection{Inhibitor synthesis}

The reagents used in this trial were purchased from Sigma Aldrich. The used coconut and palm oils were industrial-grade Oleofinos. The fatty amide was prepared through the direct aminolysis of oil, as we reported previously [17]. The synthesis to obtain the calcium salt was through a well know saponification process of coco and palm oil as shown in Figure 1 [18]. Inhibitor agent was formulated in a natural wax and in mineral oil (AVATAR brand). Natural wax produced by stingless bees (Melipona beecheii Benneth) native from America was purchased from Cosmopolitan Drugstore.
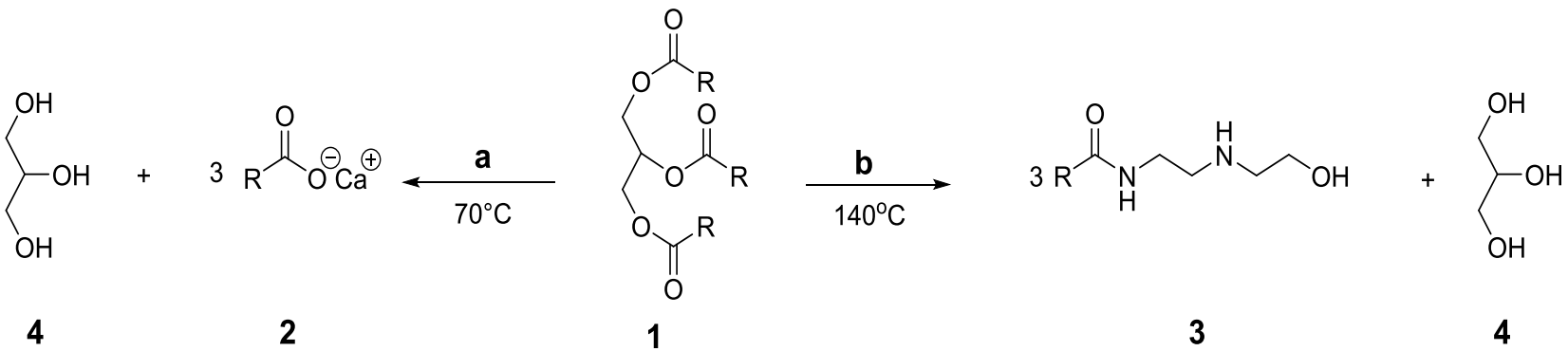

Figure 1. Synthesis of fatty acid calcium salt (2) and fatty acid $N$-[2-[(2-hydroxyethyl)amino]ethyl]amide (3). Where $\mathrm{R}=$ alkyl chains of fatty acids from triglyceride (1) palm and coconut oil; and glycerol (4). The reaction conditions are as follows: a) $\mathrm{Ca}(\mathrm{OH})_{2}(4 \mathrm{~mol}), \mathrm{MeOH} / \mathrm{H}_{2} \mathrm{O}$ (1:1); b) $\mathrm{NH}_{2} \mathrm{CH}_{2} \mathrm{CH}_{2} \mathrm{NHCH}_{2} \mathrm{CH}_{2} \mathrm{OH}$ (3 mol).

\subsection{Spectroscopic characterization}

The coconut and palm oils were characterized by Gas Chromatography (GC), in order to know the fatty acid profile contained in the oil; fatty acid methyl ester was prepared and this was analyzed by GC (150302-ext-01 STE 4981) with a flame ionization detector (FID). The equipment operated with a split of 50, flow $1.8 \mathrm{ml} / \mathrm{min}$, and separation was carried out on an AT-FAME capillary column $(30 \mathrm{~m} \times 0.25 \mathrm{~mm}, 0.25 \mu \mathrm{m})$, using helium as the carrier gas. The oven temperature was at $180^{\circ} \mathrm{C}$ during $15 \mathrm{~min}$, followed by a temperature gradient at $10^{\circ} \mathrm{C} / \mathrm{min}$ up to $230^{\circ} \mathrm{C}$ and held $3 \mathrm{~min}$. Injector and detector temperatures were both $250^{\circ} \mathrm{C}$. Peaks of fatty acid methyl esters were identified by matching their relative times with those of commercial standards (FAME). Fatty $N$-[2-[(2hydroxyethyl)amino]ethyl]amide from palm oil was characterized by Mass Gas Chromatography (Ion Source Type: ESI, Ion Polarity: Positive, Scan: $50 \mathrm{~m} / \mathrm{z}-1600 \mathrm{~m} / z$, Accumulation Time: $11007 \mu \mathrm{s})$. The coconut oil, palm oil, their derived fatty $N-[2-[(2-$ hydroxyethyl)amino]ethyl]amides and fatty calcium salts were characterized by FTIR spectroscopy on film at Bruker Tensor 27 FT-IR spectrometer (Pike Miracle SingleBounce ATR Cell). To determine the molecular structure, the fatty $N$-[2-[(2-hydroxyethyl)amino]ethyl]amides was analyzed by ${ }^{1} \mathrm{H}$ and ${ }^{13} \mathrm{C}$ NMR spectroscopy in a $400 \mathrm{MHz}$ Avance III Bruker. 


\subsection{Testing material}

Coupons made of 1018 carbon steel were cut into rectangular coupons of dimensions $7 \times 5 \times 0.3 \mathrm{~cm}$. The coupons were cleaned first with hexane and second with ethanolacetone, stored at $308 \mathrm{~K}$ in an oven during 24 hours and then weighed at room temperature on an analytical balance. The metal test panels were positioned at 15 degrees from the vertical. Three specimens were placed by formulation to get the average weight loss. Specimens were taken out every 24 hours. The coupons were cleaned with inhibited hydrochloric acid, washed with surfactant-water mixture and dried at $333 \mathrm{~K}$ in an oven according to ASTM G1. They were cleaned and weighed at the same way. The corrosion rate was calculated from the weight loss measurements by using the following relationship (ASTM-G1-03):

$$
\text { Corrosion rate }(\mathrm{mm} / \mathrm{y})=\frac{K \times W}{A \times T \times D}
$$

where $K=8.76 \times 10^{4}$, for corrosion rate calculated in millimeters per year $(\mathrm{mm} / \mathrm{y}), W=$ mass loss in $\mathrm{g}, A=$ area in $\mathrm{cm}^{2}, T=$ time of exposure in hours $(=1176 \mathrm{~h}), D=$ density in $\mathrm{g} / \mathrm{cm}^{3}\left(7.8 \mathrm{~g} / \mathrm{cm}^{3}\right.$ for steels).

The protection percentage of coated coupons was determined as follows:

Protection percentage $=\frac{\text { weight loss of blank coupon }- \text { weight loss of coated coupon }}{\text { weight loss of blank coupon }}$

\subsection{Fog conditions}

Used reagents were purchased reactive grade Fermont. Atmospheric corrosion tests were performed in a fog chamber Q-Fog Cyclic Corrosion tester, model CCT 600 Q-LAB. Three different atmospheres were simulated: marine, rural and rural polluted. Marine environment was generated at $308 \mathrm{~K}$, according to ASTM B117 (5 wt\% $\mathrm{NaCl}$ solution). Rural environment was generated by injecting a water fog into the chamber at $311 \mathrm{~K}$ in order to increase the relative humidity to $100 \%$ (ASTM D1735). Contaminated rural environment was generated using a $0.01 \mathrm{M} \mathrm{Na}_{2} \mathrm{SO}_{4}$ solution, which at $311 \mathrm{~K}$ presents a $\mathrm{pH}=5.6$; this concentration is based on chloride-free environments contaminated [19]. For industrial-marine environment, it was used a cyclic corrosion test according to ASTM G85 (Prohesion): $0.05 \% \mathrm{NaCl}+0.35 \%\left(\mathrm{NH}_{4}\right)_{2} \mathrm{SO}_{4}$ at $\mathrm{pH} 5-5.4$, first step fog $25^{\circ} \mathrm{C} 1 \mathrm{~h}$, and second step dry $35^{\circ} \mathrm{C} 1 \mathrm{~h}$.

\subsection{Surface characterization}

Corroded specimens were analyzed in a Scanning Electronic Microscope (SEM) LEO VP 1450 whereas corrosion products were characterized with a D2 Phaser, Bruker equipment with a $\mathrm{Cu} K_{\alpha}$ radiation. 


\section{Results and discussion}

\subsection{Inhibitor characterization}

The content of fatty acids in the palm and coconut oil determined by GC is shown in Table 1. The major fatty acids contained in palm oil are palmitic acid (saturated) and oleic acid (unsaturated), whereas for the coconut oil, the saturated lauric acid is the most abundant, as reported in the literature [20,21]. The CG-M results, Table 1, present three compounds at a retention time of 20,20.7 and 21.6 minutes. The integration corresponds to $8.8 \%, 55.7 \%$ and $35.5 \%$ respectively. These three compounds were identified by masses according to their molecular ion peak $\left(\mathrm{M}^{+}\right)$: linoleic amide (367.4), palmitic amide (343.4) and oleic amide (369.4) respectively.

Table 1. Fatty acid composition of palm and coconut oil.

\begin{tabular}{ccccc}
\hline Fatty acids & Structure & Type of fatty acid & Palm oil (wt.\%) & Coconut oil (wt. \%) \\
\hline Capric acid & C10:0 & Saturated & - & 8.27 \\
Lauric acid & C12:0 & Saturated & - & 55.91 \\
Miristic acid & C14:0 & Saturated & - & 18.75 \\
Palmitic acid & C16:0 & Saturated & 35.12 & 8.19 \\
Stearic acid & C18:0 & Saturated & 4.32 & 2.9 \\
Oleic acid & C18:1 n-9 cis & Unsaturated & 45.74 & 5.26 \\
Linoleic acid & C18:2 n-6 cis & Unsaturated & 10.23 & 0.71 \\
Linolenic acid & C18:3n-3 cis & Unsaturated & 0.44 & - \\
Arachidic acid & C20:0 & Unsaturated & 0.41 & - \\
\hline
\end{tabular}

The yield of fatty acid calcium salt (2) and fatty acid $N$-[2-[(2-hydroxyethyl)amino]ethyl]amide (3) was quantitative. The amide and triglyceride characterization by IR spectroscopy of palm and coconut oil is shown in Figure 2. At $1743 \mathrm{~cm}^{-1}$ appears a very strong signal for the $\mathrm{C}=\mathrm{O}$ stretching vibration. This signal is shift to lower frequency at $1642 \mathrm{~cm}^{-1}$ for fatty $N$-[2-[(2-hydroxyethyl)amino]ethyl]amide. The spectrum of fatty calcium salts derived of coconut and palm oil, reported somewhere else [22] showed two double strong bands at 1573,1538 and $1466,1418 \mathrm{~cm}^{-1}$, corresponding to symmetric and asymmetric vibration of carbonyl group of acid salt and strong band at $410 \mathrm{~cm}^{-1}$ for ionic interaction $\mathrm{O}-\mathrm{Ca}^{+}$, as reported for salt acid [22]. 


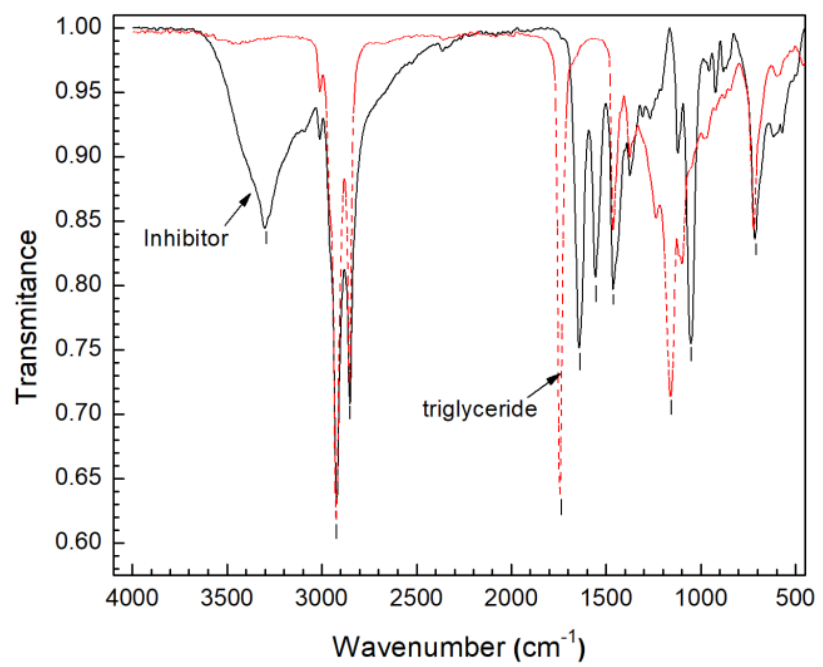

Figure 2. IR spectra of $N$-[2-[(2-hydroxyethyl)amino]ethyl]amide and triglyceride.

The fatty $N$-[2-[(2-hydroxyethyl)amino]ethyl]amide from palm oil without purification was characterized by ${ }^{1} \mathrm{H}$ and ${ }^{13} \mathrm{C}$ NMR spectroscopy, Figure $3 \mathrm{a}$. This product is composed mainly of palmitic and oleic amides. The signals of the fatty amides in lower concentration are overlapped by the main compounds. ${ }^{1} \mathrm{H}$ NMR $\left(400 \mathrm{MHz}, \mathrm{CD}_{3} \mathrm{OD}, \delta=\right.$ 4.834 and $3.299 \mathrm{ppm}): \delta(\mathrm{ppm})=0.89\left(\mathrm{t}, J=6.8 \mathrm{~Hz}, 3 \mathrm{H},-\mathrm{CH}_{3}\right), 1.28\left(\mathrm{~m}, 24 \mathrm{H},-\mathrm{CH}_{2}\right)$, $1.59\left(\mathrm{t}, J=7.2 \mathrm{~Hz}, 2 \mathrm{H},-\mathrm{CH}_{2} \mathrm{CH}_{2} \mathrm{CO}\right), 2.02\left(\mathrm{~m}, J=6 \mathrm{~Hz}, 1 \mathrm{H},-\mathrm{CH}_{2} \mathrm{CH}=\mathrm{CH}\right), 2.18(\mathrm{t}, J=$ $7.2 \mathrm{~Hz}, J=8 \mathrm{~Hz}, 2 \mathrm{H}, \mathrm{CH} 2 \mathrm{CO}), 2.72\left(\mathrm{~m}, 4 \mathrm{H},-\mathrm{CH}_{2} \mathrm{NHCH}_{2}\right), 3.29\left(\mathrm{~m}, 2 \mathrm{H},-\mathrm{CH}_{2} \mathrm{OH}\right), 3.64$ $\left(\mathrm{t}, J=5.2 \mathrm{~Hz}, J=5.6 \mathrm{~Hz}, 2 \mathrm{H},-\mathrm{NHCH}_{2}\right), 5.33(\mathrm{td}, 1 \mathrm{H},-\mathrm{CH}=\mathrm{CH}) \cdot{ }^{13} \mathrm{C} \mathrm{NMR}(400 \mathrm{MHz}$, CD3OD, $\delta=48.99): \delta=14.42\left(\mathrm{CH}_{3}\right), 23.72\left(\mathrm{CH}_{2}\right), 26.95(\mathrm{C} 3), 30.36(\mathrm{C} 4), 28.12$ $\left(\mathrm{CH}_{2} \mathrm{CH}=\mathrm{CHCH}_{2}\right), 30.23,30.32,30.43$ and $30.61\left(\mathrm{CH}_{2}\right), 33.06\left(\mathrm{CH}_{2} \mathrm{CH}_{2} \mathrm{CH}_{3}\right), 37.15$ $\left(\mathrm{CH}_{2} \mathrm{CO}\right), 39.85\left(\mathrm{CONHCH}_{2}\right), 48.36\left(\mathrm{CH}_{2} \mathrm{NH}\right), 52.01\left(\mathrm{CH}_{2} \mathrm{CH}_{2} \mathrm{OH}\right), 61.47\left(\mathrm{CH}_{2} \mathrm{OH}\right)$, 130.88 and $130.79(\mathrm{CH}=\mathrm{CH}), 176.63(\mathrm{C}=\mathrm{O})$.

The fatty $N$-[2-[(2-hydroxyethyl)amino]ethyl]amides from coconut oil without purification was characterized by ${ }^{1} \mathrm{H}$ and ${ }^{13} \mathrm{C}$ NMR spectroscopy. This product is composed mainly of lauric amide, Figure $3 \mathrm{~b}$. The signals of the fatty amides in lower concentration are overlapped by the main compound. ${ }^{1} \mathrm{H}$ NMR $\left(300 \mathrm{MHz}, \mathrm{CDCl}_{3} \delta=\right.$ $7.3 \mathrm{ppm}): \delta(\mathrm{ppm})=0.88\left(\mathrm{t}, J=6.9 \mathrm{~Hz}, 3 \mathrm{H},-\mathrm{CH}_{3}\right), 1.25\left(\mathrm{~s}, 16 \mathrm{H},-\mathrm{CH}_{2}\right), 1.61(\mathrm{~m}, J=$ $\left.7.5 \mathrm{~Hz}, 2 \mathrm{H},-\mathrm{CH}_{2} \mathrm{CH}_{2} \mathrm{C}=\mathrm{O}\right), 2.18\left(\mathrm{t}, J=7.5 \mathrm{~Hz},-\mathrm{CH}_{2} \mathrm{C}=\mathrm{O}\right), 2.78\left(\mathrm{~m}, 2 \mathrm{H},-\mathrm{NHCH}_{2} \mathrm{CH}_{2} \mathrm{OH}\right)$, $3.00\left(\mathrm{~s}, 2 \mathrm{H},-\mathrm{CONHCH}_{2} \mathrm{CH}_{2}\right), 3.37\left(\mathrm{q}, J=5.7 \mathrm{~Hz}, 2 \mathrm{H},-\mathrm{CH}_{2} \mathrm{OH}\right), 3.68(\mathrm{~m}, 2 \mathrm{H}$, $\left.-\mathrm{CONHCH}_{2}\right), 5.33(\mathrm{~s}, 1 \mathrm{H}, \mathrm{OH}), 6.51(\mathrm{~s}, 1 \mathrm{H}, \mathrm{NH}) .{ }^{13} \mathrm{C} \mathrm{NMR}(300 \mathrm{MHz}, \mathrm{CDCl} 3 \delta=77)$ : $\delta=14.07\left(\mathrm{CH}_{3}\right), 22.61\left(\mathrm{CH}_{2} \mathrm{CH}_{3}\right), 25.72\left(\mathrm{CH}_{2} \mathrm{CH}_{2} \mathrm{CO}\right), 28.96,29.27,29.30,29.46$ and $29.57\left(\mathrm{CH}_{2}\right), 31.85\left(\mathrm{CH}_{2} \mathrm{CH}_{2} \mathrm{CH}_{3}\right), 36.68\left(\mathrm{CH}_{2} \mathrm{CO}\right), 38.94\left(\mathrm{CONHCH}_{2}\right), 48.58\left(\mathrm{CH}_{2} \mathrm{NH}\right)$, $50.95\left(\mathrm{CH}_{2} \mathrm{CH}_{2} \mathrm{OH}\right), 60.68\left(\mathrm{CH}_{2} \mathrm{OH}\right), 173.91(\mathrm{C}=\mathrm{O})$. The corresponding signals for the glycerol by-product are almost insignificant at $3.5 \mathrm{ppm}$. 

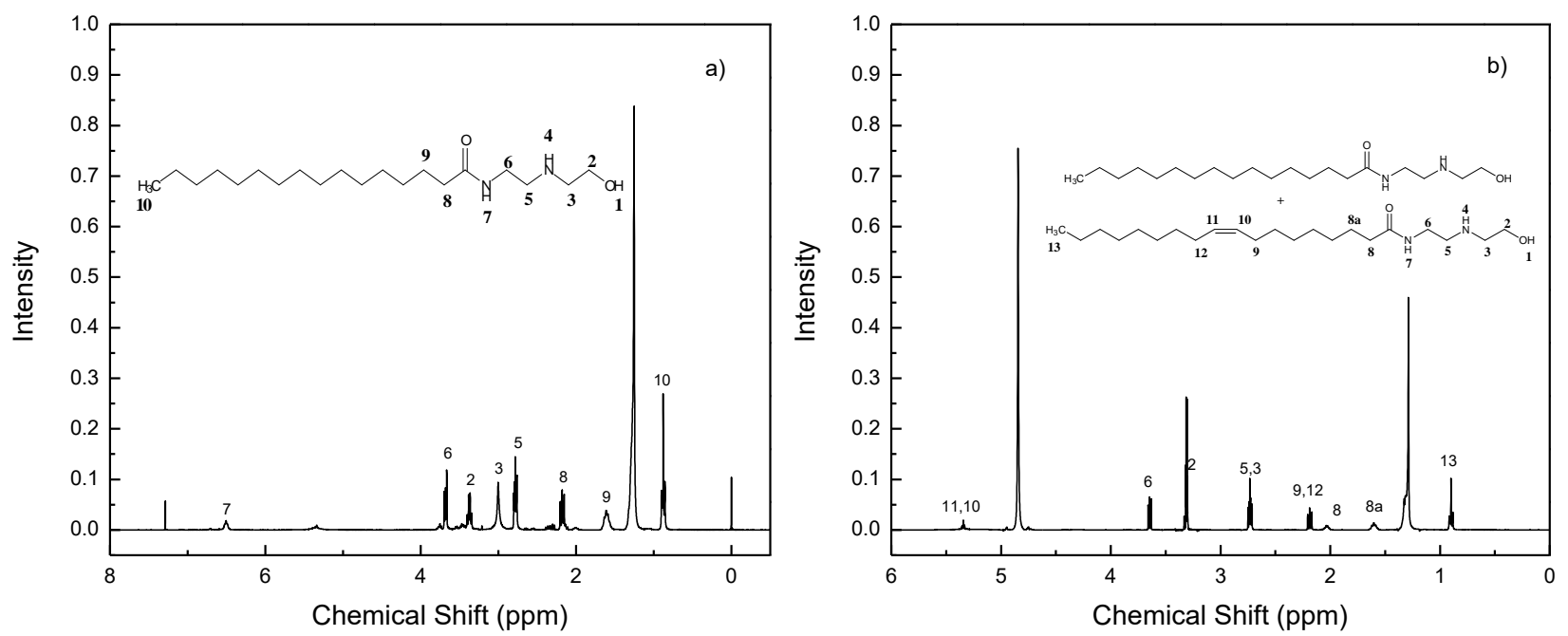

Figure 3. ${ }^{1} \mathrm{H}$ NMR spectra of main fatty $N$-[2-[(2-hydroxyethyl)amino]ethyl]amide from a) coconut oil and b) palm oil.

\subsection{Inhibitor formulation with mineral oil and natural wax}

The fatty amides and fatty calcium salt were formulated at different concentrations with natural wax and mineral oil. In order to find the concentration of greatest protection against corrosion, several concentrations were formulated and applied as spreadable grease to carbon steel coupons. These coupons were exposed to marine atmosphere (ASTMB117) during 72 hours. It was found that the synergy between the fatty amide and the surfactant had the greatest protection against corrosion. The appropriate concentration found of active compounds, was a relationship, in wt.\%, 2:1 of fatty amide and fatty calcium salt respectively. These compounds were formulated in mineral oil. It was found that the waxamide ratio 4:1 exhibited the best protection efficiency, being the ratio of 1 to 3.5 parts of wax-mineral oil. The fatty amide was purified in order to eliminate de glycerol, with two washes of brine. This fatty amide was formulated in the same optimal concentration in order to know the effect of glycerol by-product in the effectiveness of inhibiting corrosion. The weight loss measurements for the inhibitor agent with and without glycerol were almost similar, the difference was in order to $0.055 \mathrm{~g}$, giving a better efficiency the inhibitor agent with glycerol.

The process to obtain the formulation was through to pulverized the fatty calcium salt in a mortar and sift to 80 mesh particles. After, this was dissolved in mineral oil at $343 \mathrm{~K}$ and $450 \mathrm{rpm}$ during one hour. Subsequently the fatty amide was slowly added under vigorous stirring at $600 \mathrm{rpm}$ and finally the natural wax was added at the same temperature. 


\subsection{Fog conditions}

Five formulations were applied onto the steel carbon surface: Fatty amides derived from palm oil (PWO) and fatty amides derived from coconut oil (CWO) with their respective fatty calcium salt were formulated in natural wax (W) and mineral oil (O). These formulations were compared with two commercial products based on calcium sulfonate as inhibitor agent; the first commercial product (SWO) has a mixture of mineral oil and microcrystalline wax as vehicles, whereas the second commercial product (SO) contained mineral oil and an aliphatic dissolvent. Finally, a mixture of grease and mineral oil (WO) was applied as reference in a relationship 1:4.

Weight loss measurements of the steel carbon coupons exposed to continuous humidity $(100 \%)$ at $311 \mathrm{~K}$ during a period of 336 hours were performed for each formulation as well as the data for unpainted, bare steel, and the results are shown in Figure 4a. All formulations present an increase in the weight loss as exposure time increases, with the highest weigh loss value exhibited by unpainted, bare steel, indicating an excellent protection during the whole testing time. However, the inhibitor formulation SWO protects well within the first 96 hours. After this period the weight loss increases considerably, and towards the end of the tests it exhibited the highest weight loss value, behaving as the formulation based only on wax and oil without corrosion inhibitor. Otherwise, the formulations based on fatty amide presents a good excellent performance, since the weight loss values were nearly two orders of magnitude lower than those obtained for unpainted steel, as it was the case for the coconut oil-base paint.

On the other hand, corrosion rate values, Figure $4 \mathrm{~b}$, show a trend to decrease with time for unpainted steel, whereas the different coatings had an erratic behavior during the first 100 hours of exposure, but after this time they had a trend to decrease. As expected, the corrosion rate for bare steel was higher than those obtained with the coatings, obtaining the lowest value, $0.005 \mathrm{~mm} / \mathrm{y}$ for fatty amide derived from coconut oil (CWO), nearly two orders of magnitude lower than that obtained for unpainted steel. Qualitatively none of the coupons presented rust formation within 336 hours. All formulations presents a good efficiency for indoor environments or outside in rural environments. These results are better than those reported by Ghanbarzadeh et al. for the calcium sulfonate base inhibitor in oil [10]. Normally, this kind formulation is applicable for materials in storage. So, the exposure time in fog conditions is short; considering that 24 hours of exposure in fog chamber equivalents two months in field, the coco-amide base formulation has a life time greater than two years, considering the studies for carbon steel in fog cabinet compared in field by Montoya and collaborators [5]. 

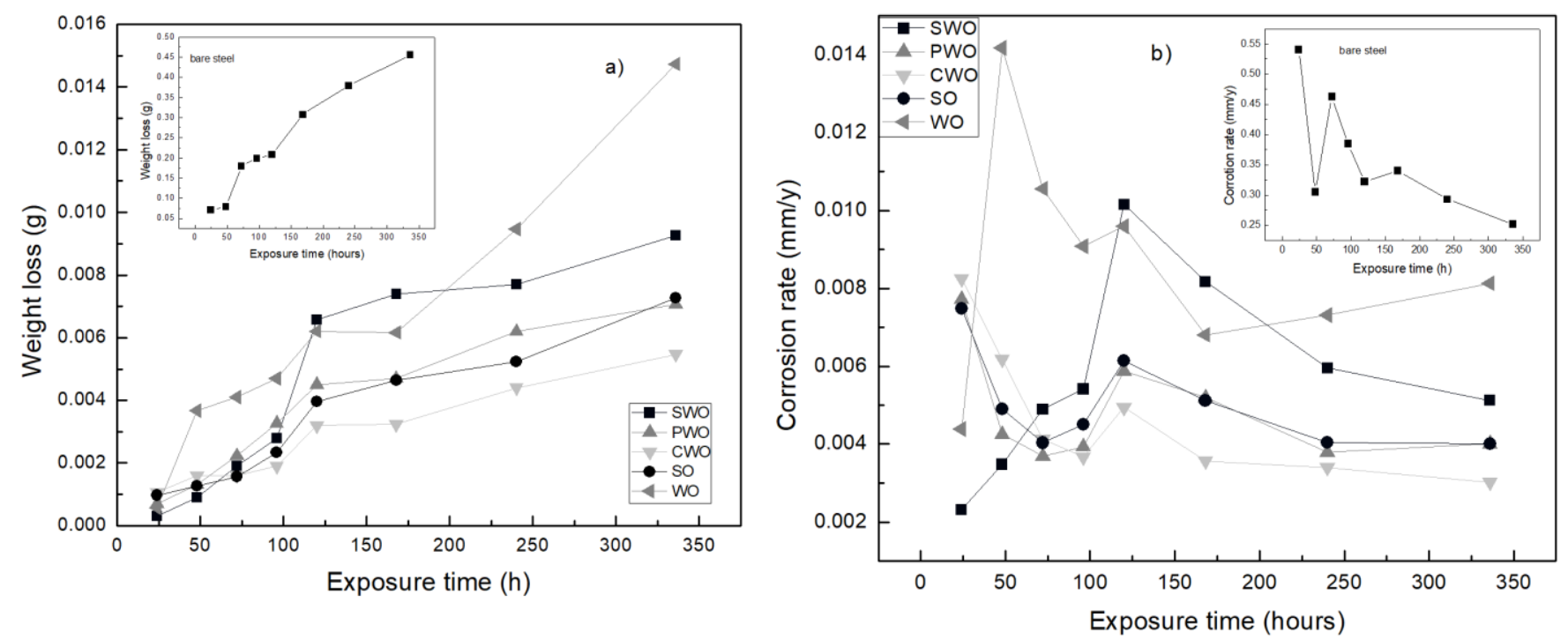

Figure 4. Weight loss measurements and corrosion rate of carbon steel with and without inhibitor, in a rural environment.

The factors affecting the atmospheric corrosion mainly are the wetting time and the amount of contaminant species deposited. Where the wetting time is the time where the temperature and humidity are beyond $0^{\circ} \mathrm{C}$ and $80 \%$, respectively, and the contaminant species deposited is the amount of $\mathrm{SO}_{4}^{2-}$ or $\mathrm{Cl}^{-}$deposited [23]. The corrosion rate directly dependent on the environment to which materials are exposed. In this work, small sulfate ions concentration was used in accelerated fog conditions, in order to known the efficiency of the temporary coating on carbon steel, for outdoor environments (storage or transport pieces) or agricultural machinery in rural-urban areas.

The weight loss measurement and corrosion rates as function of time of the carbon steel exposed to continuous humidity containing sulfate ions in an accelerate fog chamber during 168 hours are shown in Figure 5. The presence of sulfate ions accelerated the weight loss results, as can be seen if we compare Figure 5a and Figure 4a. In addition to this, it is also clear the increase in the weight loss values as the exposure time increases. The formulation based on sulfonate and oil (SO) has a short efficiency as function of time, since its weight loss value dramatically increases after 50 hours of exposure, reaching values similar to those obtained for unpainted steel. The commercial formulation containing microcrystalline wax (SWO) had a better protection than the SO did. Corrosion rate values, Figure 5b, were lower for painted steel, obtaining the lowest values for the formulations containing palm- and coconut-based amides. Nevertheless, the coupons covered with these two formulations presented corrosion products after 24 hours of exposure in this environment contaminated with sulfates. On the contrary, formulation based on fatty amide and calcium salt (PWO and CWO) presented the best efficiency over time, with weight loss values one order of magnitude lower than that obtained for unpainted steel, whereas in the rural environment the decrease in the weight 
loss value was two orders of magnitude. Qualitatively the PWO formulation did not present any formation of corrosion products within the 168 hours of test. In the contaminated rural environment, the pollution of $\mathrm{SO}_{4}^{2-}$ strongly influences the corrosion behavior in the later stages compared with rural environments. The corrosion rate remains below $0.0125 \mathrm{~mm} / \mathrm{y}$ and almost constant until $168 \mathrm{~h}$, compared to the rural environment whose fluctuations remain in a larger range until its linear behavior after 240 hours.
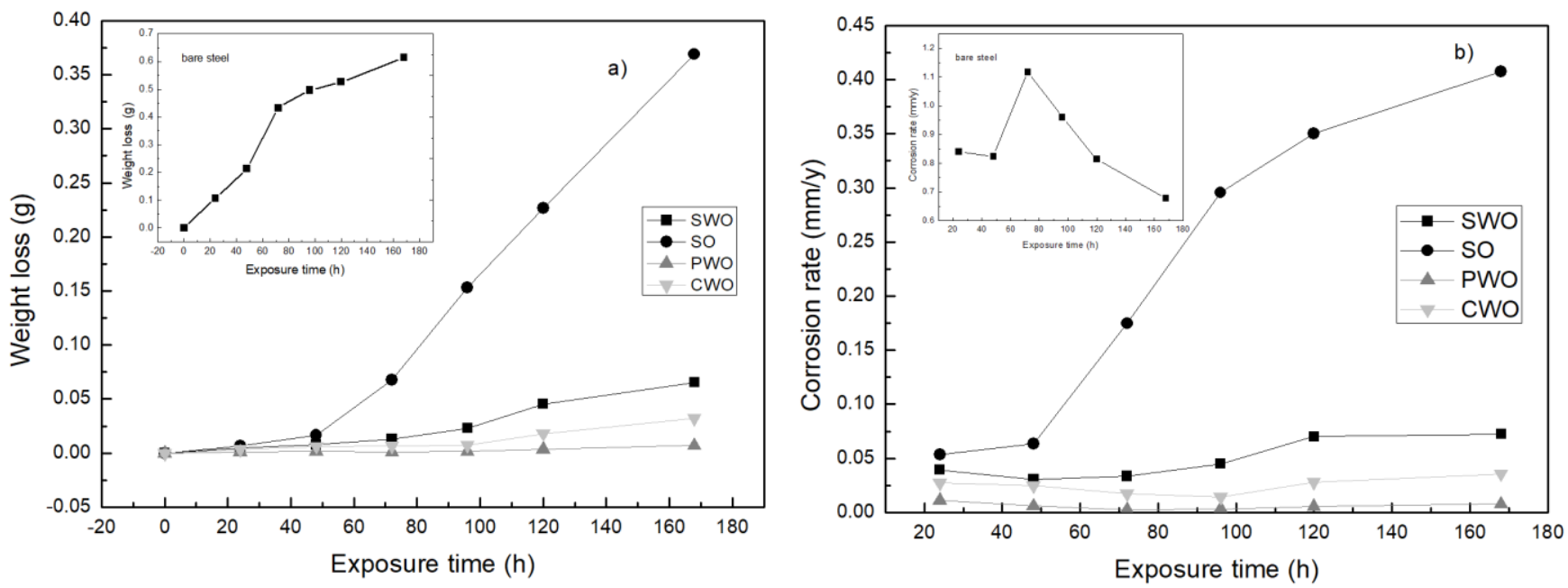

Figure 5. Weight loss measurements and corrosion rate of carbon steel with and without inhibitor, at contaminated rural environment (low $\mathrm{SO}_{4}^{2-}$ ) in fog chamber.

The palm-based amide formulation had lower weight loss values than those obtained with coconut-base amide in sulphate media. The palm-based amide formulation (PWO) was evaluated and compared with sulfonate based formulation (SWO) in an aggressive environment with high chloride content, based on ASTM B117 standard used to evaluate coatings for marine environments. Weight loss and corrosion rate values for this environment are given in Figure 6. It is possible to observe that the amide based formulation presents lower weight loss and corrosion rate values than those obtained with the sulfonate formulation and unpainted steel. For amide formulation, the corrosion rate values increase after 72 hours of exposure and rust formation are observed, whereas for sulfonated formulation, rust formation was observed after 48 hours of exposure.

Comparing the three environments and their factors, the $\mathrm{Cl}^{-}$ions containing environment is the most aggressive condition, as shown in Figure 6. These results illustrate that effect of the wetting time and the presence of $\mathrm{Cl}^{-}$and $\mathrm{SO}_{4}^{2-}$ on the corrosion rate are visible after 72 hours for carbon steel with inhibitor. On the other hand, there are few studies linking accelerated conditions of laboratory studies and field conditions [12]. Studies reported during an exposure time of 24 hours were extrapolated to two month at field. For this reason, weight loss measurements and corrosion rate were carried out for the 
material with inhibitor every 24 hours, for marine and industrial environments. The palm based formulation was applied to carbon steel every 24 hours during 12 days of exposure to the cyclic corrosion test. The inhibitor was removed by two forms: with inhibited acid (IA) and washed with detergent+water. Figure $7 \mathrm{a}$, shows the corrosion rate results extrapolated in the time for carbon steel protected with inhibitor. Unpainted steel showed the highest corrosion rate, which increases with an increase in the exposure time, whereas for the material washed with inhibited acid, the corrosion rate increases during the first day, and afterwards it decreases and remains almost constant during the rest of the test, exhibiting similar corrosion rate values than the material washed with detergent and water. However, in the marine-industrial environment, the for material washed with detergent and water had a corrosion value lower than $1 \times 10^{-5} \mathrm{~mm} / \mathrm{y}$ during the whole test, whereas unpainted steel had a corrosion rate value higher than $1.0 \mathrm{~mm} / \mathrm{y}$, so the palm base formulation offers and excellent protection during the test for marine environments. The temporary protective layer can be used regularly to protect parts exposed to corrosive environments.
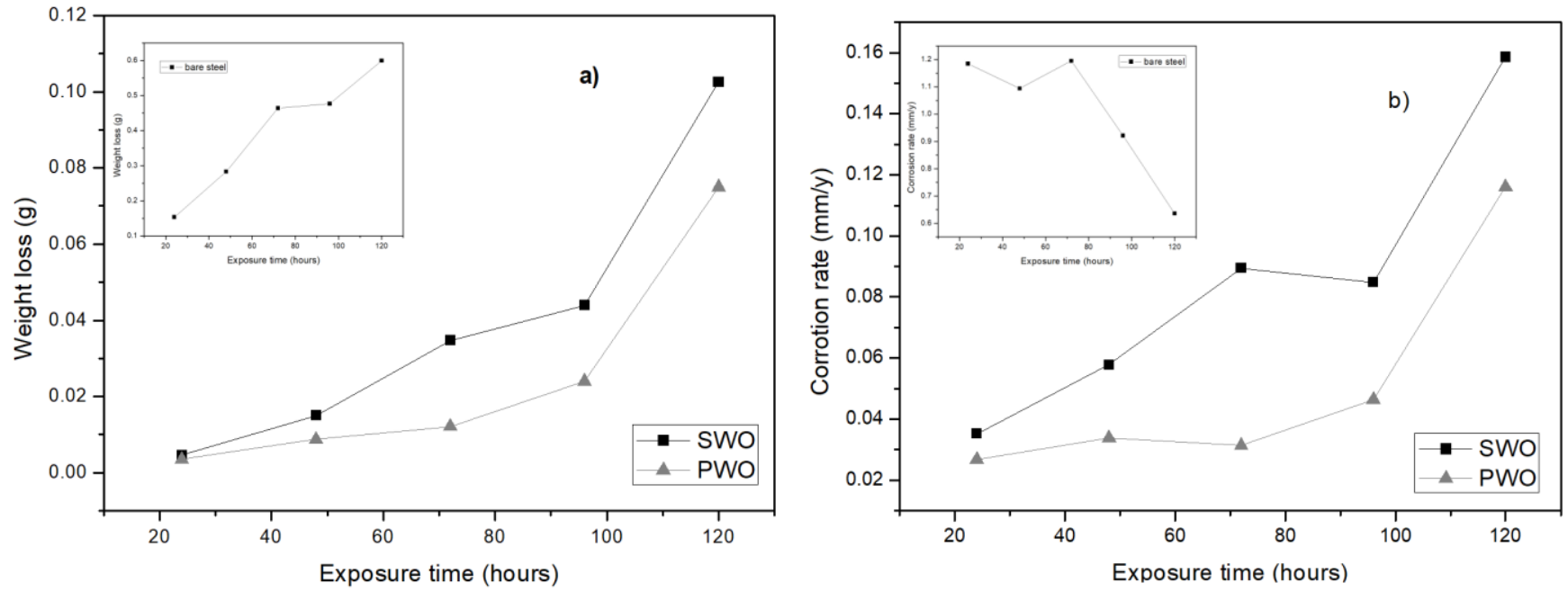

Figure 6. Weight loss measurements and corrosion rate of carbon steel with and without inhibitor, at marine environment in fog chamber according to ASTM B117.

Fatty amide and anionic surfactant formulation has an excellent protection percentage $98.4 \%$, for rural environment after $336 \mathrm{~h}$ and $98.8 \%$ for a polluted rural environment after $168 \mathrm{~h}$, Table 2. For highly corrosive environment, the formulation has an efficiently protection during a short period of time or for an application every two months. For coastal industrial environment, it had an efficiency value of $99.75 \%$. 
Table 2. Protection percentage of coated coupons in different environment.

\begin{tabular}{ccccc}
\hline $\begin{array}{c}\text { Environmental } \\
\text { Conditions }\end{array}$ & Formulation & $\begin{array}{c}\text { Final weight of } \\
\text { coupon }\end{array}$ & $\begin{array}{c}\text { Corrosion rate } \\
(\mathbf{m m} / \mathbf{y})\end{array}$ & $\begin{array}{c}\text { Protection } \\
\text { percentage (\%) }\end{array}$ \\
\hline & WO & 0.0147 & 0.4556 & 96.78 \\
Rural (336 h) & SO & 0.0073 & 0.0040 & 98.4 \\
& SWO & 0.0093 & 0.4556 & 97.97 \\
& PWO & 0.0073 & 0.0040 & 98.41 \\
& CWO & 0.0078 & 0.0043 & 98.28 \\
\hline Rural & SO & 0.369 & 0.6144 & 39.94 \\
contaminated & SWO & 0.0655 & 0.6144 & 89.34 \\
\cline { 1 - 1 } & PWO & 0.0071 & 0.0078 & 98.84 \\
Marine (120 h) & CWO & 0.0325 & 0.0359 & 94.71 \\
\hline Industrial-Marine & SWO & 0.1026 & 0.1586 & 75.06 \\
$(288 \mathrm{~h} / 24 \mathrm{~h})$ & PWO & 0.3483 & 0.5385 & 81.77 \\
\cline { 1 - 1 }$(288 \mathrm{~h} / 24 \mathrm{~h})$ & PWO & 0.0093 & 0.000006 & 99.68 \\
\hline
\end{tabular}
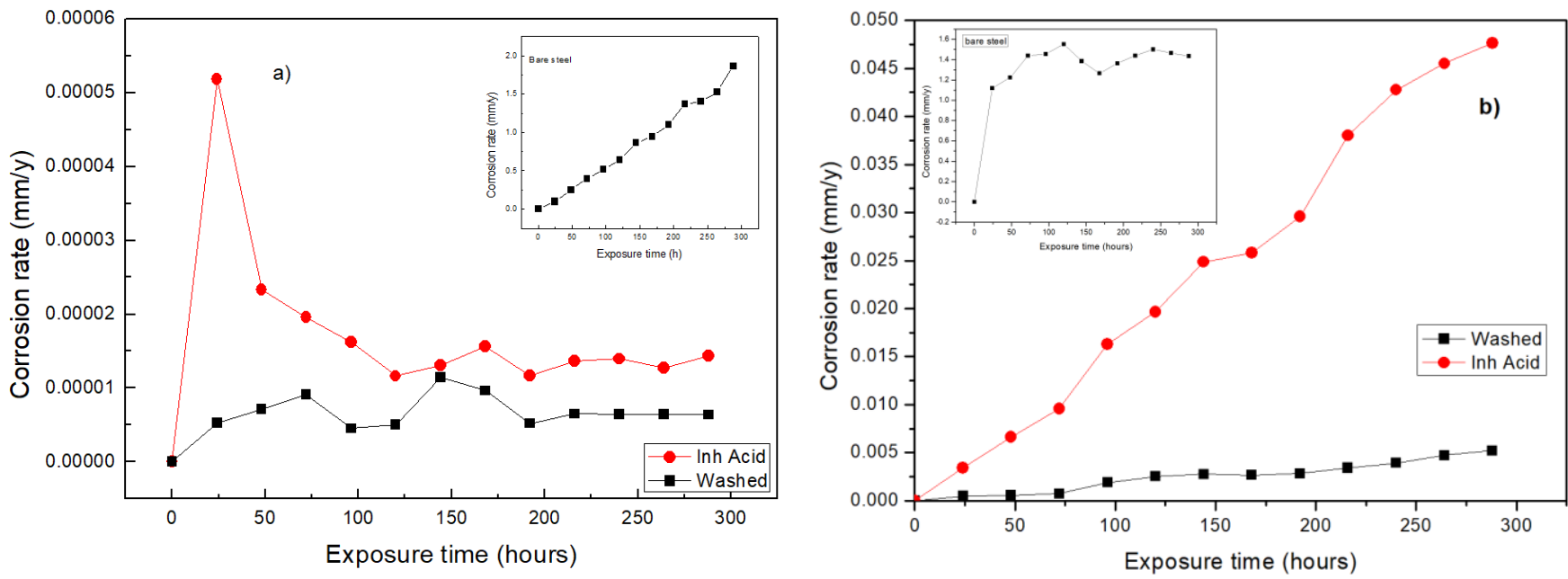

Figure 7. Corrosion rate of carbon steel with inhibitor application every 24 hours, exposed to a: a) marine and b) marine-industrial environments.

\subsection{Surface characterization}

Rust-layer formation on carbon steel is one of the most thoroughly studied systems in atmospheric corrosion. The most common early corrosion products on iron are "green rusts", mixtures of ferrous and ferric oxyhydroxides. These compounds are of transitory 
nature and involve into more stable constituents of the rust layer with prolonged exposure [15]. In order to know the influence of organic constituents in oxides formation, the rust layers obtained from the material with inhibitor exposed to marine environment, were analyzed by XRD. Figure 8 shows the corrosion products which correspond for the material without inhibitor and with inhibitor (SWO and PWO) respectively. In all spectrums, the stable forms of ferric oxyhydroxide: lepidocrocite $\gamma$-FeOOH in the first stages of exposure are observed; after that, $\alpha-\mathrm{FeOOH}$ goethite is the dominant phase. For the material with SWO film, the partly transformation of the lepidocrocite layer into magnetite $\left(\mathrm{Fe}_{3} \mathrm{O}_{4}\right)$ with a $22.5 \%$ is found, whereas for the palm inhibitor formulation only $7.9 \%$ of $\mathrm{Fe}_{3} \mathrm{O}_{4}$ is found, together with $10.3 \%$ of maghemite $\left(\gamma-\mathrm{Fe}_{2} \mathrm{O}_{3}\right)$. The rate of atmospheric corrosion is determined both by the delivery rate of constituents to the corroding surface and by the reaction rate of reactants with the surface.

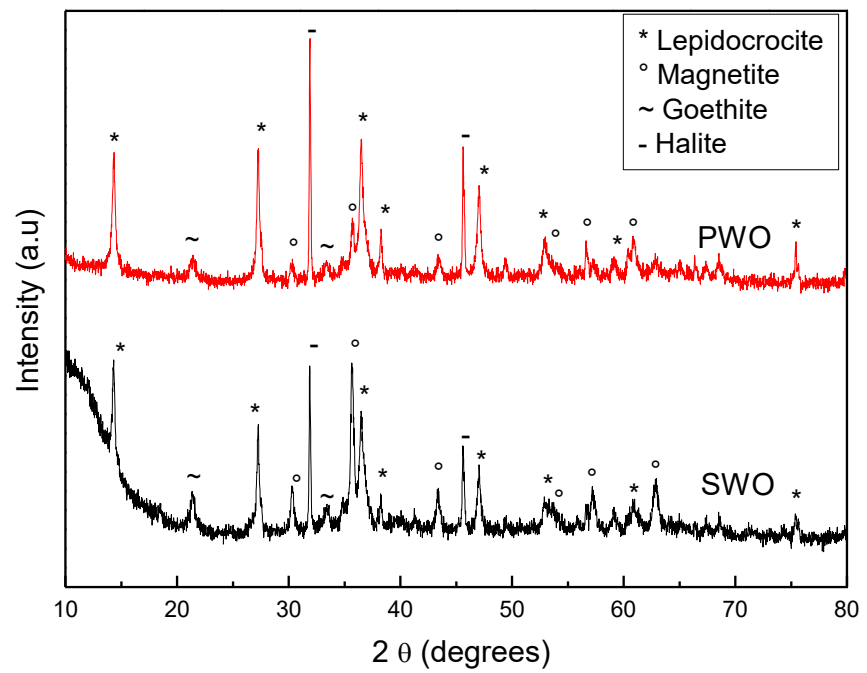

Figure 8. XRD patterns of Rust layer formed on carbon steel with and without inhibitor exposed to a marine environment.

Corroded coupons with and without inhibitor was characterized by SEM, in order to determine the type of corrosion caused by a severe marine environment and Figure 9 shows these micrographs after 96 hours of exposure. It is observed that the least severe damage caused by chloride ions atmosphere is for the material coated with the palmcoconut-based amide formulation. For without coupon, the surface shows a high density of pits due to the attack by sulfate ions. Salt spray testing provides answers which are unrealistic in the natural world, yet prohesion provides more realistic results which correlate much better with long term exterior exposure [25]. In Figure 10, it is possible to observe that carbon steel coated with a palm oil-base inhibitor shows much less damage after 96 hours to expose at wet/dry cyclic test than the unpainted material exposed to saline fog condition $(100 \% \mathrm{RH})$. 


\section{Conclusions}

Fatty amide formulations efficiently reduced the corrosion atmospheric rate in relative humidity (100\%). This study can be related to corrosion protection for materials during the storage period or indoor exposition for about two years. In a contaminated rural or ruralurban environments with minor concentrations of sulfates, the results indicate a good protection for about one year. Palm-based formulation protects more effectively than temporary sulphonate based coatings. For materials exposed to corrosive atmospheres, palm-based formulation has a long life time of protection of the material, applying it every month or 2 months.

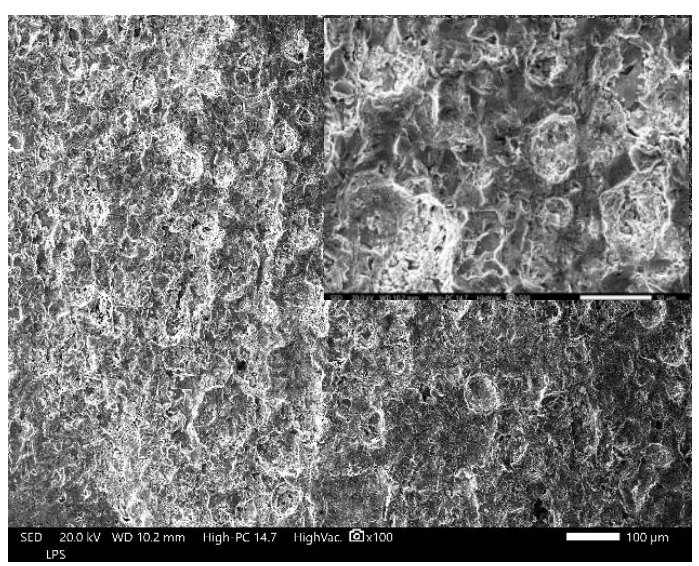

a)

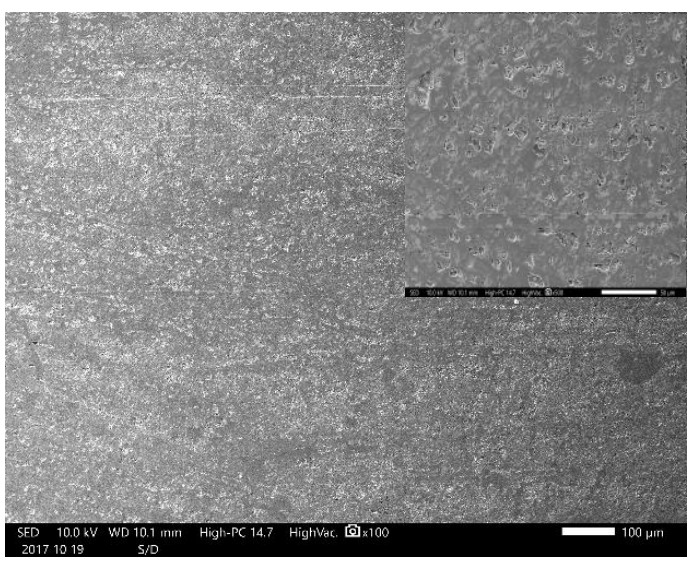

b)

Figure 9. The SEM images for steel exposed to a marine environment during 96 hours of exposure coated with: a) SWO and b) PWO.

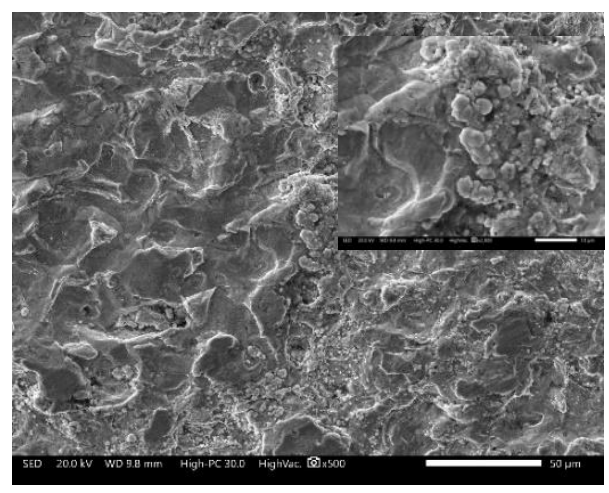

a)

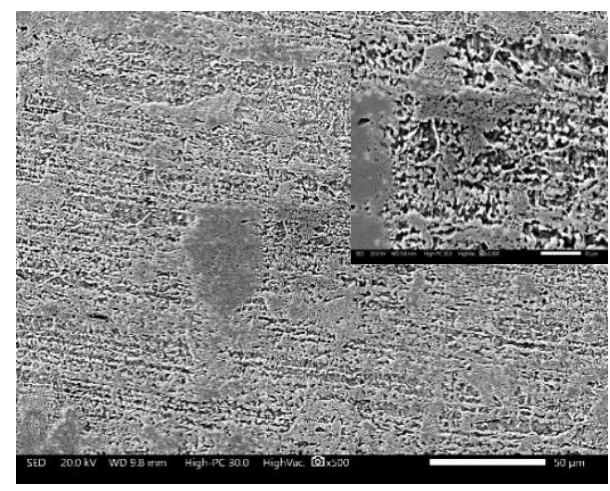

b)

Figure 10. The SEM micrographs of steel exposed to an industrial-marine environment during 96 hours: a) unpainted carbon steel and b) PWO coated carbon steel. 


\section{Acknowledgements}

M.E. Escalante Pérez is thankful to the Consejo Nacional de Ciencia y Tecnología (CONACYT, México) for the PhD scholarship. The authors thank M.C. José Juan Ramos Hernández for his support in analysis by SEM.

\section{References}

1. T. Murata, Weathering steels, in: Uhlig's Corrosion Handbook, Ed. R. Winston Revie, John Wiley and Sons, New York, 2000, p. 320.

2. S.J. Oha, D.C. Cook and H.E. Townsend, Corros. Sci., 1999, 41, 1687.

3. Y. Ma, Y. Li and F. Wang, Corros. Sci., 2010, 52, 1796.

4. B. Panda, R. Balasubramaniam and G. Dwivedi, Corros. Sci., 2008, 50, 1684.

5. P. Montoya, I. Díaz, N. Granizo and M. Morcillo, Mater. Chem. Phys., 2013, 142, 220.

6. R. Singleton, Met. Finish., 2012, 110, 12.

7. V.M. Abbasov, L.I. Aliyeva, E.K. Gasanov, Y.J. Aghazade and N.S. Rzayeva, J. Adv. Chem., 2014, 10, 214.

8. V.M. Abbasov, F.A. Amirov, S.A. Mammadkhanov, L.I. Aliyeva, Y.J. Aghazade and E.K. Hasanov, Petrochemical and Oil Refinery Processes, 2013, 44, 122.

9. A.Q. Talibov, L.I. Aliyeva, T.A. Mammadova, V.M. Abbasov, N.Q. Kerimova and S.Y. Hajiyeva, Petrochemical and Oil Refinery Processes, 2009, 40, 249

10. A. Ghanbarzadeh and E. Akbarinezhad, Prog. Org. Coat., 2006, 56, 39.

11. P.A. Schweitzer, Atmospheric Degradation and Corrosion Control, Marcel Dekker, Inc., New York, 2005, ISBN: 0-8247-7709-3.

12. N.N. Andreev and Yu.I. Kuznetsov, Int. J. Corros. Scale Inhib., 2013, 2, no. 1, 39-52. doi: 10.17675/2305-6894-2013-2-1-039-052

13. A.I. Altsybeeva, V.V. Burlov, N.S. Fedorova and T.M. Kuzinova, Int. J. Corros. Scale Inhib., 2013, 2, no. 1, 9-16. doi: 10.17675/2305-6894-2013-2-1-009-016

14. X. Luo, X. Pan, S. Yuan, S. Du, C. Zhang and Y. Liu, Corros. Sci., 2017, 125, 139.

15. Ch. Verma, D.S. Chauhan and M.A. Quraishi, J. Mat. Env. Sci., 2017, 8, 4040.

16. S.H. Yoo, Y.W. Kim, K. Chung, S.Y. Baik and J.S. Kim, Corros. Sci., 2012, 59, 42.

17. N. Velazquez-Torres, H. Martinez, J. Porcayo-Calderon, E. Vazquez-Velez, J.G. Gonzalez-Rodriguez and L. Martinez-Gomez, Green Chem. Lett. Rev., 2018, 11, 1.

18. P. Chaloner, Organic Chemistry, CRC Press, Taylor and Francis Group, 2015, p. 719.

19. M.E. Escalante-Perez, J. Porcayo-Calderon, E. Vazquez-Velez, M. Casales-Diaz, J.G. Gonzalez-Rodriguez and L. Martinez-Gomez, Int. J. Electrochem. Sci., 2016, 11, 374.

20. A.J. Anderson, L.C. Almeida, E.A. Silva, C.F. Lucio, S. Eguesa, E. Franceschia, M. Fortunya, A.F. Santosa, J. Araujoc and C. D. Sousac, J. Supercrit. Fluids, 2013, 81, 245. 
21. J.M. Jung, J. Lee, D. Choi， J.I. Oh， S.R. Lee， J.K. Kim and E.E. Kwon, Energy Conver. Manage., 2017, 145, 308.

22. J.B. Lambert, H.F. Shurvell, D. Lightner and R.G. Cooks, Organic Structural Spectroscopy, Prentice Hall, 1998, p. 175.

23. M. Morcillo, B. Chico, I. Díaz and and H. Cano, Corros. Sci., 2013, 77, 6.

24. C.T. Leygraf and E. Graedel, Atmospheric Corrosion, Electrochemical Society Series, Wiley Interscience, 2000, p. 149.

25. N.D. Cremer, Prohesion Compared to Salt Spray and Outdoors, Presented at Federation of Societies for Coatings Technology Paint Show, 1989.

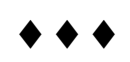

